\title{
Vampires in Video Games: Mythic Tropes for Innovative Storytelling
}

\author{
Roberto Dillon \& Anita Lundberg
}

James Cook University, Singapore

\begin{abstract}
This paper discusses traditional vampire tropes as a tool for innovation and novel experiences in the history of video games. A selection of games and vampires will be analysed in terms of gameplay and storytelling elements to show how the rich mythology and folklore that characterises these liminal beings can be successfully employed in a variety of settings and contexts. We draw on examples from the early days of video games with titles like "Dracula" (Imagic for Intellivision, 1982) set in a virtual London and evoking European folklore, to the rich possibilities offered by "Vampire the Masquerade: Bloodlines" (Activision for PC, 2004) which conjures up the sub-tropical New Orleans vampire tradition, and then turn to the latest experimental games using the example of "Tainted" (ITE/NUS for PC, 2016), which taps into the rich Pontianak vampire-ghost myths of the Malay Archipelago. Different experiences will be discussed via explanatory lenses - such as Labov's $(1972,1997)$ narrative analysis and the AGE/6-11 framework (Dillon, 2010, 2016) - to gain insights into how to build compelling myth-based narrative in games in original and surprising ways. The paper also analyses how specific vampire myths reflect socio-cultural issues of particular times and places. Thus, every telling of such myths - whether though oral tales, novels, cinema, or video games - brings the myth alive to engage with liminal or repressed aspects of a society.
\end{abstract}

Keywords: videogame analysis, game studies, storytelling, myths, vampires, Pontianak, tropics, liminal

\section{Vampire tropes and video games}

In their short but rich history, video games have relied on many different sources for inspiration 1 and for crafting engaging interactive stories and emotional experiences. As exemplified in books outlining innovative and genre-defining games since the birth of the industry, liminal and monstrous beings based in mythology, folklore and popular culture, have been widely referenced - from ghosts to dragons and beyond (Mott, 2010; Dillon 2011). Within this context, perhaps surprisingly, vampires have been used more sparingly than other monstrous creatures such as, 
for instance, the popular zombies. While there have been successful franchises that pit players against a vampire as the game's antagonist or the world's ultimate evil - as in the very successful "Castlevania" series (published by Konami since 1986) - few have used vampires to craft a rich storytelling experience where the playable character is herself a vampire following her or his own morally dubious, if not altogether evil, agenda. There have, however, been a few notable exceptions, and some of these are the topic of this paper. Arising from the early days of the medium is the simple, but highly original, "Dracula" (by Imagic for the Intellivision console); later, in 2004, a very complex game under the title "Vampire the Masquerade: Bloodlines" (by Activision/Troika Games for PC) emerged; and recently the small, experimental, but highly original PC game, "Tainted" (by ITE/NUS), based on the Malay female vampire-ghost, has appeared.

In discussing these games, we will have a chance to better understand how traditional vampire tropes based in mythology and folklore can be used in innovative ways and, in doing so, have an opportunity to link together well-established gaming storytelling analysis methods with more experimental game analysis tools. This further allows an opportunity to offer a possible analytical approach merging narratology and ludology features, suggesting new ground for discussing a theoretical debate started with Frasca (1999) and Aarseth (2001) and then continued in Frasca (2003), Galloway (2006), and others.

Additionally, the paper opens up to a more theoretical-contemplative dimension, for the incorporation of liminal ${ }^{1}$ monstrous beings in video games also gives a sense of how vampires live on through their continued manifestations in contemporary society's new storytelling forms and practices. We argue that such stories are important, whether in the form of myth, novel, film or game, they are never 'mere fiction'. Vampires arise and give voice to socio-culture issues faced in particular times and places; issues that may otherwise remain repressed.

\section{Storytelling and game analysis}

When discussing storytelling in an interactive setting like video games, it is necessary to draw a clear distinction between the "designer's story" and "player's story". As explained by Rouse (2004), the former refers to the story set up originally by the game designers, including all the unchangeable and scripted events players will necessarily go through during the game; while the latter includes the unique events each player will experience in their own playthrough: how battles are won or lost, the specific strategies adopted, or, in the most complex games, how the actual narrative is shaped by unique player's decisions and choices. Simple games may rely exclusively

\footnotetext{
${ }^{1}$ Liminality is the threshold of border crossings in any form. Liminal in the context of this paper appears on several registers. It refers to nondualist being and spaces that exist in-between definitive states. These include vampires as between living and dead, the Pontianak vampire-ghost as between ghost and vampire, the multiplicity of identity, heterotopic spaces, haunted spaces, the filmic screen, and video games themselves.
} 
eTropic 16.1 (2017): 'Tropical Liminal: Urban Vampires \& Other Bloodsucking Monstrosities' Special Issue I 48

on players' stories at their most fundamental level to engage players, for instance how "Pac Man"2 cleverly evaded the ghosts; while games falling into the interactive movie category, like "Dragon's Lair"3, capture players' attention by using only the designer's story. However, most high-profile games released today, especially in the RPG (Role Playing Games) genre, merge the two very effectively to ultimately allow players to feel like they are in control of their avatar's ${ }^{4}$ destiny while also living in a believable and consistent game-world where exciting underlying events are taking place.

Thus, high-profile games with their combination of players and designer's stories offer a sense of a uniquely storied world. Once identified, these unique stories can then be discussed further by applying different approaches or frameworks common to both narrative and game analysis to gain a deeper understanding of how engaging interactive experiences can be crafted and designed. In the context of this paper, we will focus our attention firstly on Labov's narrative analysis approach $(1972,1997)$ before turning to the AGE/6-11 Framework (Dillon 2010, 2016). The former has been selected since it is a well-known and established narratology tool while the latter, despite being relatively new, is an easy to apply ludology tool that has been used successfully in different academic contexts exemplified in studies by Marins et al., (2011), Kerlow et al., (2012), Lee and Liu (2016), as well as being referenced in talks by leading industry practitioners like Reichelt (2017).

Labov's (1997) approach aims at deconstructing a narrative, usually be represented as a monologue, by applying a series of definitions starting from a "narrative of personal experience" that is made up by a sequence of events organised into "clauses" and "temporal junctures". The newer AGE/6-11 framework, on the other hand, aims at identifying how specific gameplay elements emotionally resonate with players to ultimately provide an engaging experience by breaking a game down into three main layers - Actions, Gameplay and Experience - and analysing how these relate to each other. In the following examples we discuss the respective gameplay via auto-ethnographic first-hand playthrough, with the aim of uncovering useful insights as to why a specific interactive story - based on a traditional mythological liminal being such as a vampire - can still be so engaging and relevant to a modern audience.

The first example, being a relatively simple game, is well suited for trying to combine narratology and ludology approaches to fully describe the player's experience. In this example we also include a cultural history of the Dracula vampire trope. In the second case study, we shift our focus to narratology to point out how the in-game narrative can shape a gameplay related to myths as well as real world problems, and here we explore the sub-tropical New Orleans vampire genre. Lastly, the third example will underline how the myth of Pontianak, the female vampire-ghost from the

\footnotetext{
${ }^{2}$ Released by Namco in 1980

${ }^{3}$ Released by Cinematronic in 1983

${ }^{4}$ The term 'avatar' in this context is intended as an icon or figure representing the player in a video game.
} 
eTropic 16.1 (2017): 'Tropical Liminal: Urban Vampires \& Other Bloodsucking Monstrosities' Special Issue I 49

Malay Archipelago, can be a significant local heritage inspiration for novel game design ideas and approaches.

\section{"Dracula": Gothic vampire tropes for a simple player's story}

Among video game producers in the early 1980s, the California-based Imagic was one of the most well-known, having undergone a meteoric rise due to its high quality, colorful graphics and original titles for systems like the Atari $2600^{5}$ and Mattel Intellivision". "Dracula" (Figures 1 and 2) was one of their best-looking games, and apt to its namesake, it referenced common tropes of vampires as bloodsucking hunters associated with central European mythology, folklore and sightings (Pile, 2003), as exemplified most strikingly through Bram Stoker's Dracula (1897), but also the earlier short story The Vampyre; $A$ Tale by John William Polidori (1819), which was based on the romantic character of Lord Byron (as well as on Byron's own notes for a potential book). The popularity of these novels set the stage for a game that would be easily understood by European and North American audiences. The following brief analysis of the myth and folklore of the vampire is warranted as it expands our cultural and historical understanding of this trope and its importance.

The nineteenth century vampire craze spread through Victorian-era England and Europe at a time when the public was enthralled by gothic horror and in the grasp of fears regarding migrants, women's emancipation, and sexuality - including homosexuality. As the French theorist Michel Foucault argued (1979 [1976]), fears of sexuality were not in any way 'simply' repressed; rather, the era was obsessed with sexuality which became institutionalised in disciplinary discourses at this time - for instance, in law, medicine, psychiatry, etc. It is significant that such disciplinary institutionalisation carries with it the connotation of control, regulation and order; for the aim of was to bring under control aspects of society that were viewed as disruptive to the dominant social order. This analytical understanding of how the repressed is called up in the discourses of a time and place can be extended from concerns regarding sexuality to issues of women and migrants. The era was also the height of the age of colonialism which involved the political and economic expansion of England and Europe around the globe. ${ }^{7}$ Trading companies, under the protection of

\footnotetext{
${ }^{5}$ See https://en.wikipedia.org/wiki/Atari_2600

${ }^{6}$ See https://en.wikipedia.org/wiki/Intellivision

${ }^{7}$ British colonies included Malaya (Singapore, Malaysia, Sabah and Sarawak), India, Myanmar, Australia, Fiji and other Pacific Islands; French colonies were in Indochine (Vietnam, Laos, Cambodia) and the Pacific, including New Caledonia; the Dutch were in Indonesia and parts of New Guinea; the Spanish in Latin America and the Philippines; and the Portuguese in Brazil and Timor Leste. Africa was colonised by all these colonial governments, as well as by Belgium and Italy with colonial rule extending off the African coast to the islands in the Indian Ocean. The islands of the Caribbean were also subject to several colonial regimes and featured predominantly in the human trade that brought slaves from Africa to the Caribbean islands as labour for plantations.
} 
governments, were prevalent throughout the tropical regions of the world where the exploitation of resources, and humans, returned goods and wealth to London and European colonial capitals. No matter how far colonies were from colonial power centres, their presence was constantly felt - the imaginary of foreign places and people imported back to the metropole with goods and human cargoes (see Pile, 2003). As Edward Said theorized in his work on Orientalism (1979 [1978]), foreign places under colonial rule were imagined in certain ways. Orientalism referred most specifically to the Arab world, but the theory is also readily applied to imaginaries of the colonial tropics. Said (1979 [1978]) argues that the world is mapped, narrated, collected and recorded from a Western point of view and that the Western colonial empires imagined - in a very real sense - the orient (and other colonised places, including across the tropics) as the nonEuropean 'Other' - essentially feminine and irrational, and variously depicted as exotic and erotic; primitive and savage. It was this cultural background in which the tale of Count Dracula, and the tropes we still associate with the gothic vampire genre, thrived.

The 1980s Imagic video game, "Dracula", drawing on elements of the colonial European vampire trope, was set in a nineteenth century looking London. In a very well-crafted side-scrolling action game, the player took the role of Count Dracula and needed to roam the streets at night looking for potential human prey. The Count could also lure people out of their homes by knocking at their doors. At the same time, however, the vampire was vulnerable to computer controlled policemen (in the form of traditional London Bobbies), armed with sharpened wooden stakes, as well as white wolves who constantly chased after him. The players could attempt to evade the policemen and wolves by transforming into a bat, but then other predators - for instance, a vulture with fangs - would show up and turn the vampire once again from hunter into hunted. When dawn approached, Dracula had to run back to the cemetery to hide in his grave, only to wake the following night to repeat the hunt at a higher difficulty level and against more aggressive enemies.

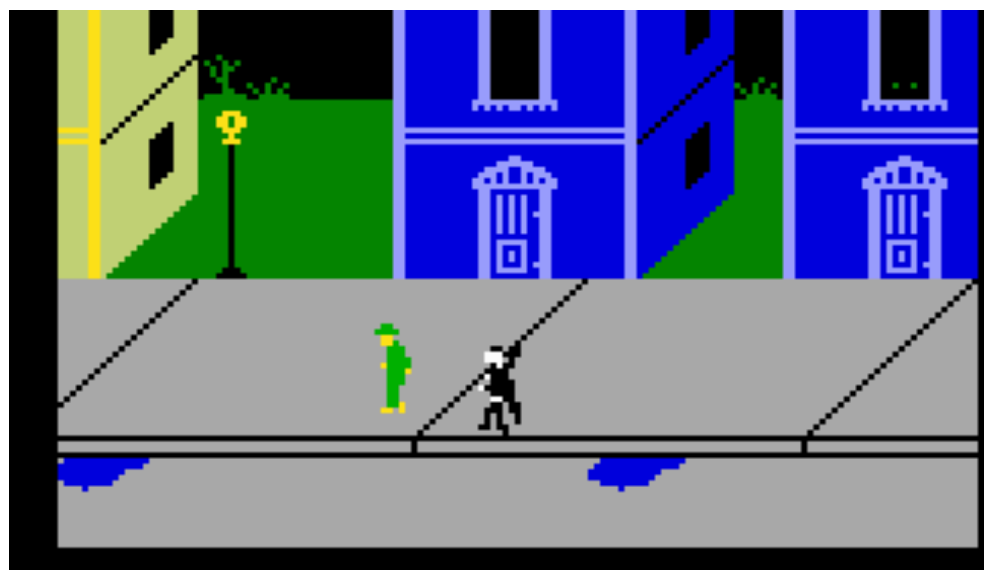

Figure 1. Dracula, Imagic for Intellivision, 1983: Night

Roaming the streets at night looking for prey. Note the pixel-sized glowing green "eyes" behind a window in the far-right building; the player could actually call the person out by knocking at their door. However, the person would only appear if they had not observed Dracula kill anyone on the street. 


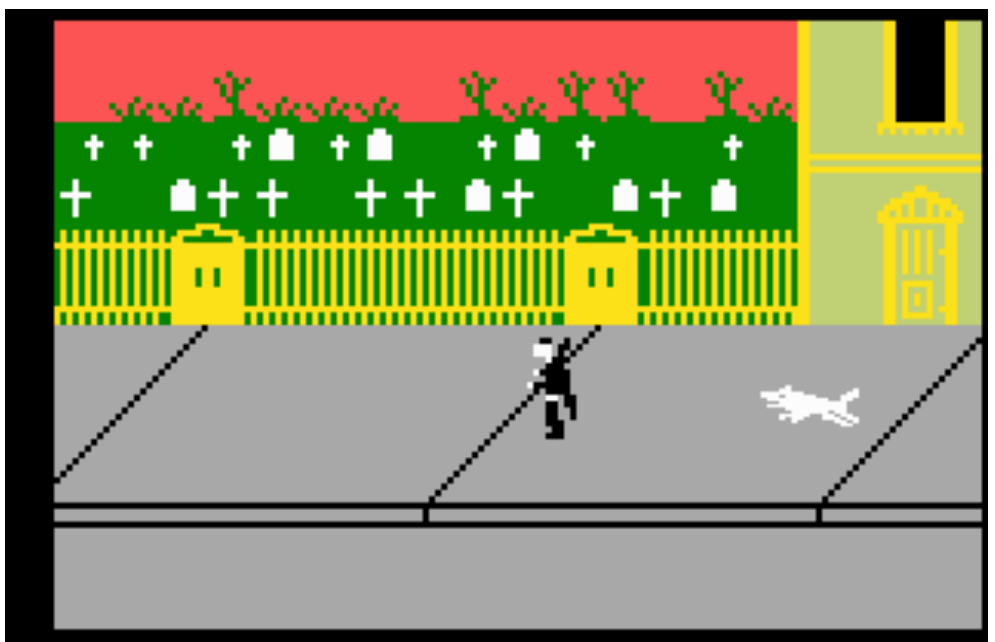

Figure 2. Dracula, Imagic for Intellivision, 1983: Dawn

It is almost dawn and Dracula is being chased by a white wolf. Luckily for the player, the graveyard is close by - a safe haven can be reached before it is too late.

Plenty of graphical details and the possibility of playing as the vampiric anti-hero made this game an innovative and groundbreaking title for the day. While there was no real "designer's story" to speak of from a narrative perspective, the various gameplay possibilities provided fertile ground for interesting, though short, "player's stories". Following Labov's (1997) structural and temporal analysis, we could discuss part of a hypothetical playing session in the form of a narrative of personal experience structured into a set of bound, restricted, and free clauses, defined as follows:

$\begin{array}{lll}\text { a } & \text { restricted } & \text { I rise from the grave } \\ \text { b } & \text { restricted } & \text { and start roaming the streets, } \\ \text { c } & \text { restricted } & \text { The moon rises with me. }\end{array}$

--- end of 1st temporal juncture

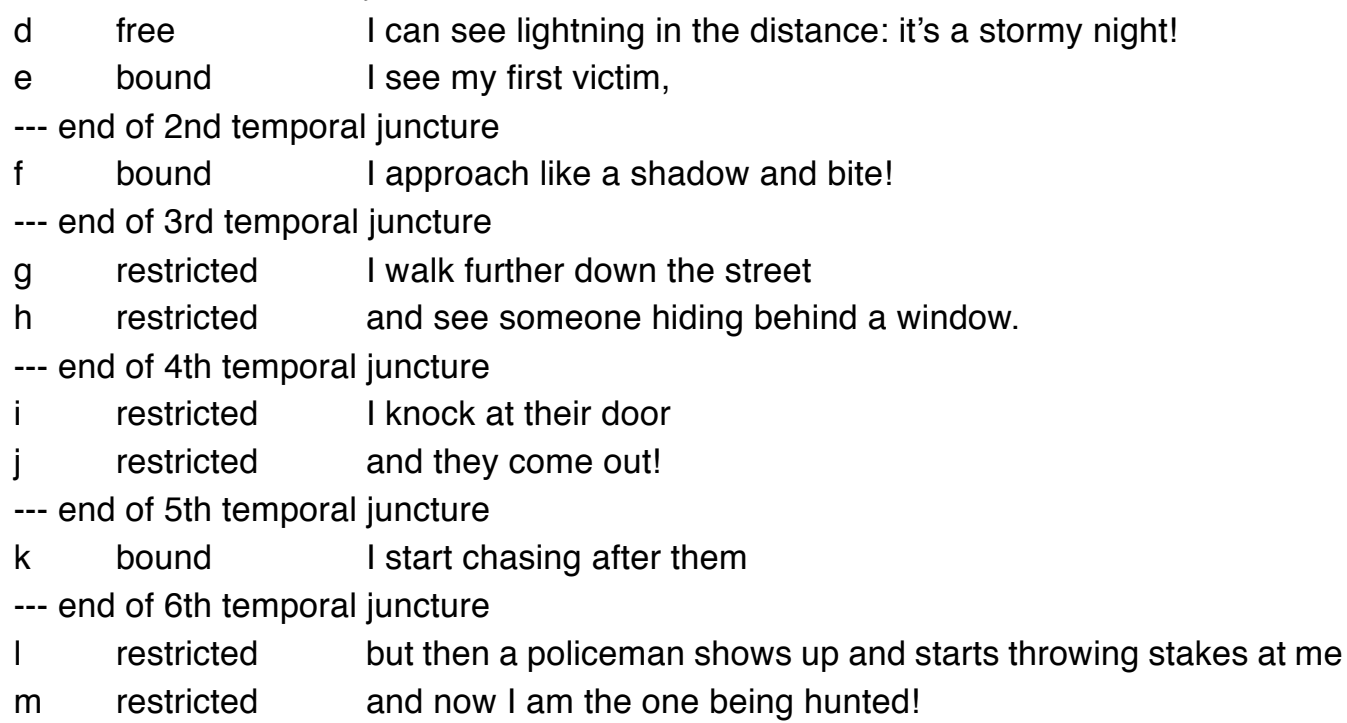


eTropic 16.1 (2017): 'Tropical Liminal: Urban Vampires \& Other Bloodsucking Monstrosities' Special Issue I 52

--- end of 7th temporal juncture

$\begin{array}{lll}\text { n } & \text { bound } & \text { I transform into a bat to fly away. } \\ \text {--- end of 8th temporal juncture } & \\ \text { o } & \text { restricted } & \text { A fanged vulture tries to grab me. } \\ \text { p } & \text { restricted } & \text { I transform back into Dracula to escape the vulture's fangs } \\ --- & \text { end of 9th temporal juncture } \\ q & \text { restricted } & \text { but it's almost dawn now } \\ r & \text { restricted } & \text { so I go back to the safe haven of my grave, } \\ \text { s } & \text { restricted } & \text { ready for another night of action. }\end{array}$

As can be seen above, there are a sequence of clauses with a first temporal juncture that sets up the stage for the unfolding action (clauses a to $\mathrm{c}$ ). A free clause describing the settings (d) follows, and then two short temporal junctures depicting the first assault (e and f). This is followed by a series of junctures depicting increasingly hectic phases of gameplay where the player alternates between being the hunter and being hunted - both in the streets of the city and in the stormy sky - before finding a safe haven back in his original heterotopic space of the graveyard. ${ }^{8}$ This is a very straightforward type of narrative that nonetheless manages to feel unique to the player, fulfilling the player's story requirements that are so important to game designers in order to effectively engage players.

From a game analysis and ludology perspective, "Dracula" was one of the case studies originally discussed in Dillon's AGE framework (2010, p. 91), where it was pointed out that the gameplay focused on alternating phases of chasing and escaping to make players feel like both hunters and prey (Figure 3). It is very interesting, then, to see how the narrative clauses pointed out earlier by using Labov's analysis can be mapped onto the AGE framework (Table 1). By connecting the two, we can easily dissect how the player's personal narrative developed within the game and how it managed to resonate with the set of emotions the game designer originally intended.

For example, we can appreciate how environmental details make the game world visually attractive and likely to resonate with the "colour appreciation" instinct ${ }^{9}$ as defined in the 6-11 Framework, as well as make a lasting impression on players and be reported as free clauses (e.g. the lightning in the background). The game then relies on well-known 'Dracula' vampire tropes depicting the main character as a night stalker who can be killed by being impaled with a stake in order to build a simple yet effective loop able to fill the narrative with a tight sequence of restricted and bound clauses.

\footnotetext{
${ }^{8}$ Heterotopias, in a Foucauldian analysis, are 'other spaces' that offset what is considered normative. They are worlds within worlds that mirror, but upset, what is outside in society. The cemetery is a classic example of a heterotopia (Foucault, 1984). This is also a liminal space in which society is topsy-turvy. Thus, that Dracula is at 'home' in a space in which humans feel out of place is significant, as is the inversion of the vampire seeking this sanctuary as the sun rises, only to rise again when the sun sets.

${ }^{9}$ i.e. crafting a visually rich and attractive environment to stimulate exploration.
} 
eTropic 16.1 (2017): 'Tropical Liminal: Urban Vampires \& Other Bloodsucking Monstrosities' Special Issue I 53

In other words, thanks to a quick succession of phases where the player is either chasing victims or escaping attackers, the gameplay is designed to trigger different emotional states, in which "excitement" and "fear" are the most relevant to this example, and act as catalysts for a short personal narrative - a simple story that is unique to that particular playthrough (i.e. a player's story). ${ }^{10}$ By referencing many common and well established gothic Dracula vampire tropes that were instantly familiar to players, and then switching the player's perspective to become the antihero in their own story, the game managed to craft an experience that was truly innovative back in the 1980s when it was originally released.

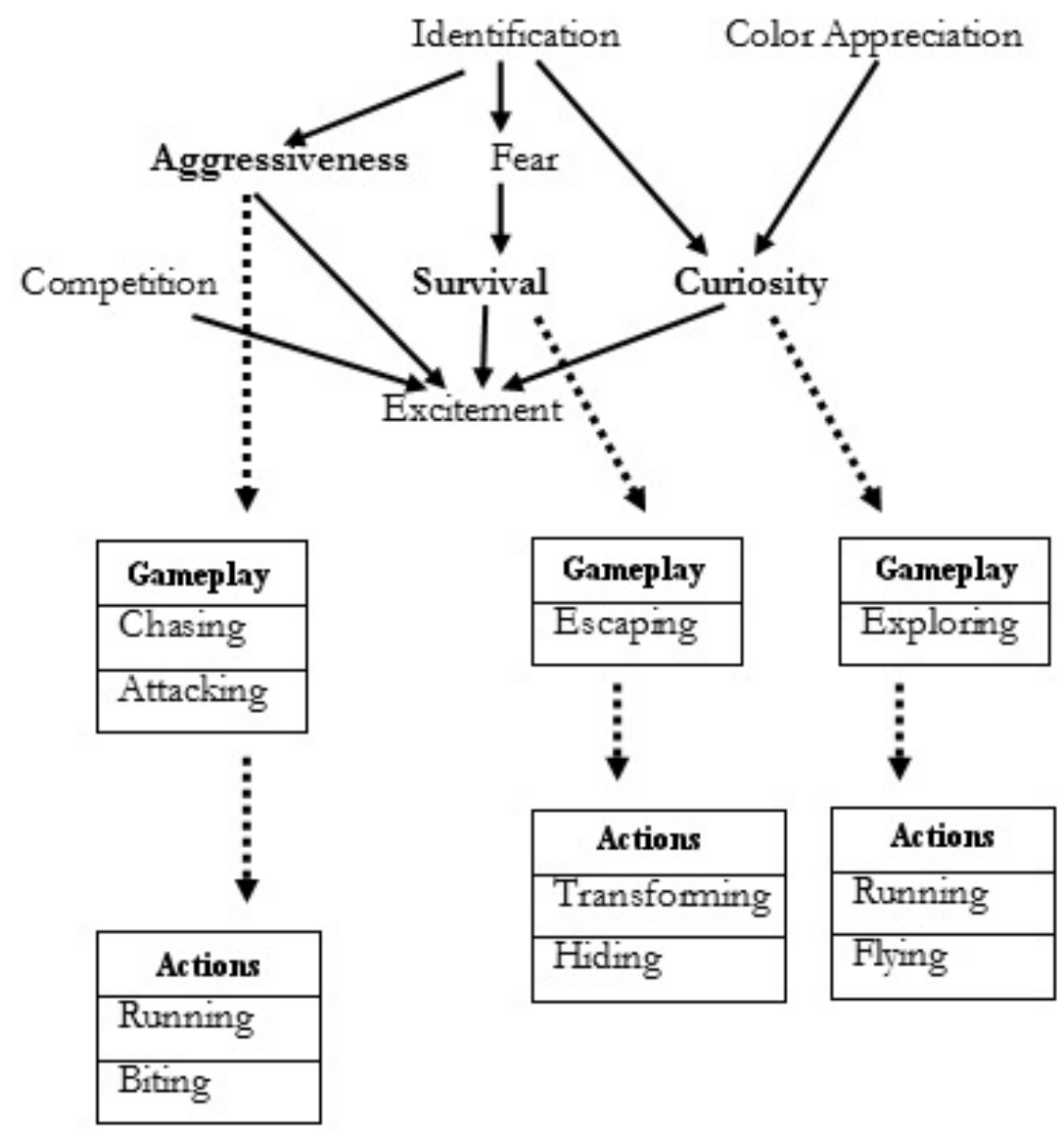

Figure 3. "Dracula", Imagic for Intellivision, 1983. AGE Analysis.

Breaking down the game into three different layers: a low level set of Actions the player can perform by using the controller, the emergent Gameplay these will originate, and a high level view of a set of possible emotions (experience) that such gameplay is likely to arouse in the process.

${ }^{10}$ While in narrative analysis, there is a formal difference between "narrative" and "story" since the former needs at least a temporal juncture which is not necessarily required for the latter, game design as a field of study is often less rigorous in its definitions; so, in this context, a "player's story" can be considered as synonymous of "narrative of personal experience". 
eTropic 16.1 (2017): 'Tropical Liminal: Urban Vampires \& Other Bloodsucking Monstrosities' Special Issue I 54

Table 1. Correspondence between Labov's Narrative Analysis and AGE Framework for "Dracula."

\begin{tabular}{|c|c|c|c|}
\hline Clause & Actions & Gameplay & Experience \\
\hline I rise from the grave & - & - & Self-Identification \\
\hline and start roaming the streets, & Running & Exploring & Curiosity \\
\hline The moon rises with me & - & - & Color Appreciation \\
\hline $\begin{array}{l}\text { I can see lightning in the distance: } \\
\text { it's a stormy night! }\end{array}$ & - & - & Color Appreciation \\
\hline I see my first victim & - & - & Excitement \\
\hline I approach like a shadow and bite! & Attacking, Biting & Chasing & $\begin{array}{l}\text { Aggressiveness, } \\
\text { Excitement }\end{array}$ \\
\hline I walk further down the street & Running & Exploring & Curiosity \\
\hline $\begin{array}{l}\text { and see someone hiding behind a } \\
\text { window }\end{array}$ & - & - & Excitement \\
\hline I knock at their door & Knocking & Chasing & Aggressiveness \\
\hline and they come out! & - & - & Excitement \\
\hline I start chasing after them & Running & Chasing & $\begin{array}{l}\text { Aggressiveness, } \\
\text { Excitement }\end{array}$ \\
\hline $\begin{array}{l}\text { but then a policeman shows up and } \\
\text { starts throwing stakes at me }\end{array}$ & - & - & Fear \\
\hline and now I am the one being hunted! & - & - & Fear \\
\hline I transform into a bat to fly away & Transforming, Flying & Escaping & Survival \\
\hline A fanged vulture tries to grab me & - & - & Fear \\
\hline I transform back to escape its fangs & Transforming & Escaping & Survival \\
\hline but it's almost dawn now & - & - & Color Appreciation \\
\hline $\begin{array}{l}\text { so I go back to the safe haven of my } \\
\text { grave }\end{array}$ & Hiding & Escaping & Survival \\
\hline ready for another night of action & - & - & Self-Identification \\
\hline
\end{tabular}


eTropic 16.1 (2017): 'Tropical Liminal: Urban Vampires \& Other Bloodsucking Monstrosities' Special Issue I 55

\section{"Bloodlines": A steamy world of vampire masquerade}

Ostensibly set in the city of a Los Angeles, but oozing vampire tropes associated with the New Orleans vampire tradition of the American sub-tropical south, "Vampire the Masquerade: Bloodlines" is a very complex game that effectively merges an interesting designer's story - filled with original and well-rounded characters - with unique player's stories. The game can be played following many different approaches and styles made possible by giving players not only well crafted levels to navigate according to different strategies, but also by offering numerous and varied avatars complete with complementary skills. Here, as in the earlier "Dracula" for Intellivision, players take the role of a vampire, but a highly customizable one, including a sex/gender choice (however still no transgender options in the early 2000s), and various physical and personality traits that can be modified and improved throughout the game. ${ }^{11}$ Vampires in this game are grouped according to clans: there are fashionable and attractive vamps, like the "Toreador", who connote the eroticised 'native' and prefer to use their seductive skills over fighting; at the other extreme, the deformed "Nosferatu" are portrayed as primitivised 'savages' who need to hide in the sewers; and there are also various exoticised vampires in between - giving players a wide variety of choices that have rarely been seen in any game before or since. As with the orientalism discussed as part of the cultural history background to gothic Dracula, we can see that the vampires of "Bloodlines" - in the tradition of the Southern vampire genre - suggest aspects of orientalism through the motifs of eroticism, primitivism and exoticism. As with the European vampire, the New Orleans vampire has been strongly associated with the threat of otherness.

However, it is also important to note here how the settings of this game are based on modern depictions of vampires, which are portrayed as social creatures, instead of the more archaic version of the "lone hunter" so common in traditional Western imaginaries based on Bram Stoker's European Count. This, in turn, resonates with the New Orleans steamy sub-tropical vampire traditions of novels such as Interview with a Vampire (Rice, 1979) or The Southern Vampire Mysteries (Harris, 2001-2013) and the subsequent HBO TV series True Blood (Ball, HBO, 20082014). Anne Rice, in her novel Interview with a Vampire, made a significant contribution to the genre when she humanized the monster. The events of the story became narrated from a vampiric perspective, allowing the reader to become embroiled in the moral reflections and dichotomies the monster experienced as it seduced, killed and fed on the blood of victims.

Nevertheless, despite differences between the northern and southern traditions, as with the European vampire, the New Orleans vampire has been strongly associated with the threat of otherness. New Orleans was settled in the early 1700s during the period of vampire hysteria in Europe. The port grew into a city comprising a heterogeneous polyglot population of colonial Europeans - French, German and Spanish - as well as African slaves, Haitians and people of Creole descent. The city has always been imagined and experienced as highly immersed in its

${ }^{11}$ See https://en.wikipedia.org/wiki/Vampire:_The_Masquerade_\%E2\%80\%93_Bloodlines 
eTropic 16.1 (2017): 'Tropical Liminal: Urban Vampires \& Other Bloodsucking Monstrosities' Special Issue I 56

climate and surrounding environment of bayous - affected by the deathly forces of hurricanes and epidemics of tropical disease. Mosquito vector diseases have been particularly prominent in its history with yellow fever causing deaths in the tens of thousands - in 1853 alone, 7,849 died. Yellow fever deaths (as with epidemics of tuberculosis in Europe) were blamed on evil spirits which were associated with strangers and their foreign cultural practices (Carrigan, 1959). Horrors came from elsewhere to enter the city and contaminate its people.

Southern vampire literature and film has been well documented regarding references to the horror of the other portrayed through the fear of mixing cultures, races and species; and to sexuality and the dangers of mixed blood and other bodily fluids. These southern tales include allusions to French, Creole, African and Haitian cultural influences - and their historical links through slave trade, tropical plantations, and the rambling desolate mansions of colonial masters.

Aspects of the southern vampire tropes manifest in the game "Bloodlines" - for instance in characters' names - but most prominently through the complexity of identity and morality. Playable from both third and first person perspectives, "Bloodlines" does not shy away from mature content and complex storylines. In the opening scene, the player's character is seduced in a sleazy hotel room and transformed into a vampire against his/her will. Thus, from first bloodlust the scene sets into motion a myriad of adventures to follow.

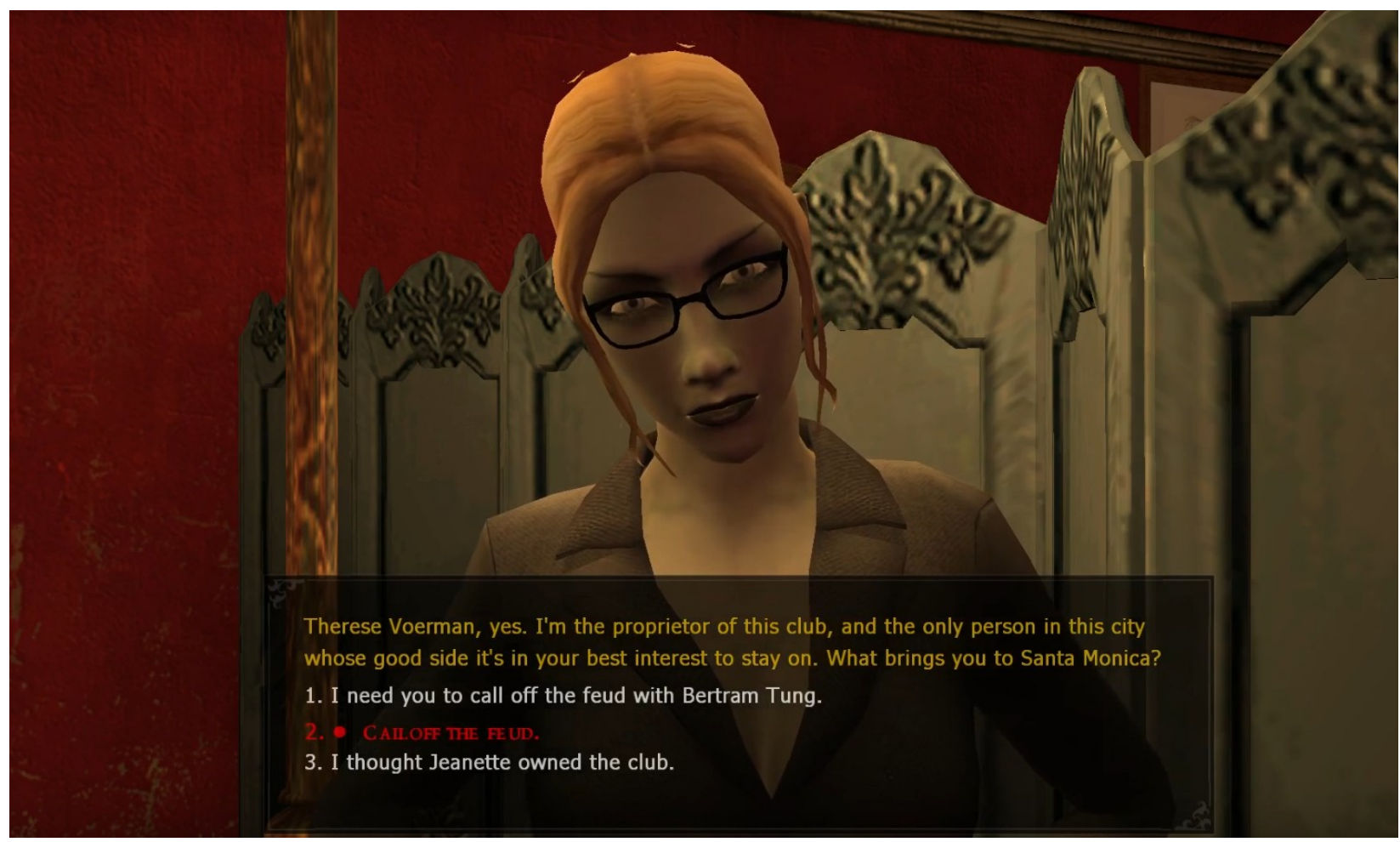

Figure 4. Meeting Therese Voerman, the cold, business savvy vampire from "Vampire The Masquerade: Bloodlines." 


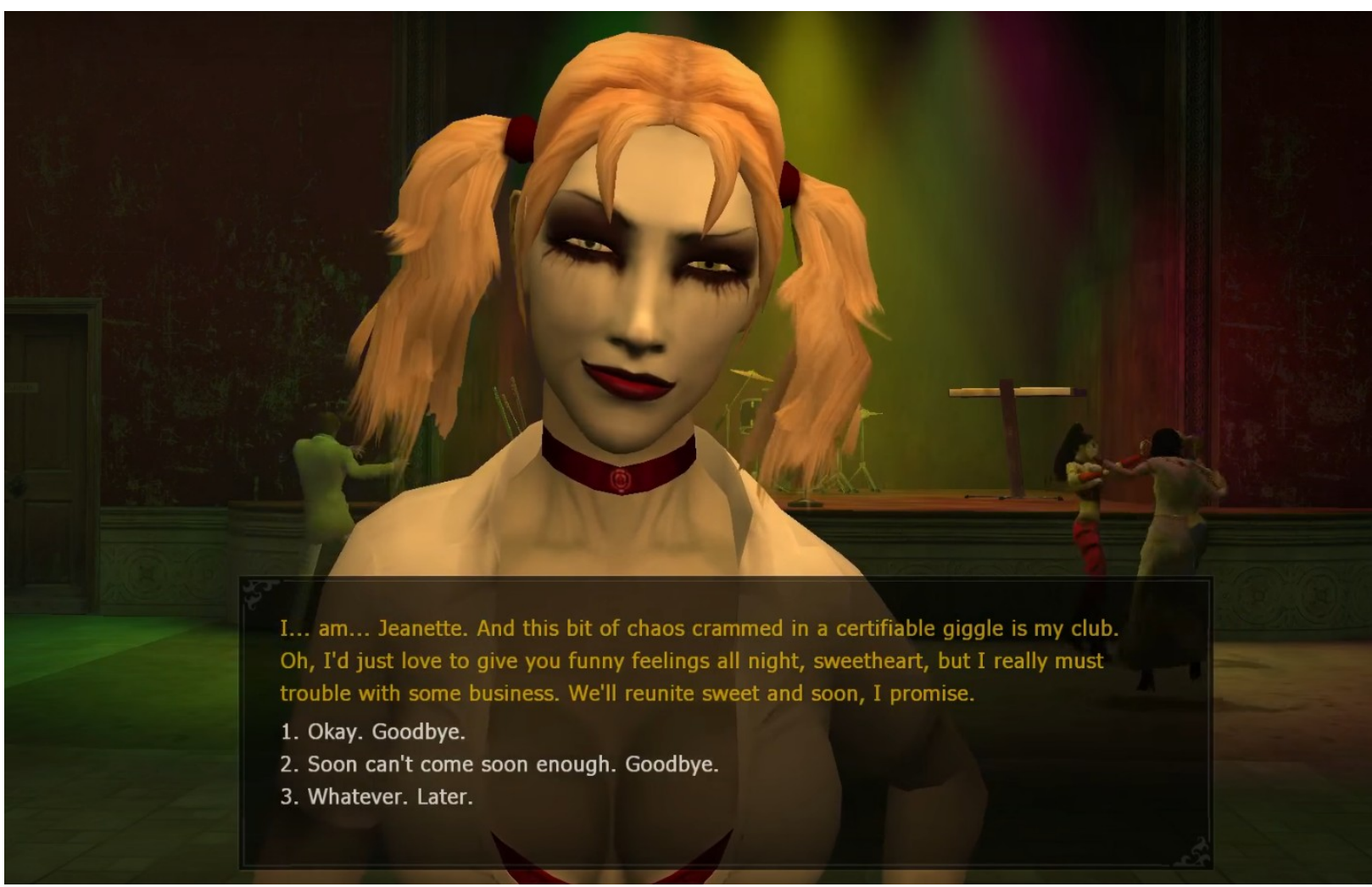

Figure 5. Therese's twin sister, Jeanette Voermann from "Vampire The Masquerade: Bloodlines."

Among the many quests and sub-quests, one that particularly stood out in reviews ${ }^{12}$, involved the twin sisters Therese and Jeanette Voerman, owners of the Asylum Nightclub in Santa Monica. The first (Figure 4) is a cold and business-minded vampire while the second is the prototype of a wild, sexy and reckless girl (Figure 5), which alludes to one twin showing aspects of a dominatrix and the other suggesting signals of a submissive - albeit, one that does not submit and will definitely bite back!

This sub-story of Theresa and Jeanette can be discussed in terms of Labov's (1972) Six Elements of Storytelling, which include the following:

1. Abstract - How does it begin?

2. Orientation - Who/what does it involve, and when/where?

3. Complicating Action - Then what happened?

4. Resolution - What finally happened?

5. Evaluation - So what?

6. Coda - What does it all mean?

12 See, for example, Rausch, Allen (November 16, 2004). "Vampire: the Masquerade", p. 2 http://pc.gamespy.com/pc/vampire-the-masquerade-bloodlines/566646p2.html 
eTropic 16.1 (2017): 'Tropical Liminal: Urban Vampires \& Other Bloodsucking Monstrosities' Special Issue I 58

An analytical reading of the sub-story indicates the following particulars:

1. Abstract: To advance in the main story, the player needs to find another NPC (non-playable character) who is in hiding to avoid the sisters' retaliation in an ongoing feud. However, before agreeing to call the feud off and make it is easy for us to find the NPC, Therese asks the player to free one of her properties from the haunting presence of an aggressive ghost so she can finally sell it for a good price.

2. Orientation: The haunted house is actually a hotel where, as the player soon finds out, a gruesome family murder, in the style of Stanley Kubrik's thriller masterpiece "The Shining" (1980), took place some time earlier.

3. Complicating Action: Once the ghost is dealt with by retrieving a precious amulet, the player gets entwined in a growing conflict between Therese and Jeanette, with a simple branching narrative and a corresponding side mission that, once over, sets the stage for an unexpected plot twist: Jeanette and Therese are actually the same person suffering from an extreme case of split personality (Figure 6)!

4. Resolution: In a dramatic confrontation, the player must ultimately decide whether to side with one specific personality and have the other disappear for good; or manage to keep both "sisters" alive and on friendly terms with one another.

5. Evaluation: Regardless of the specific final outcome, the surviving personality will be grateful and let the player proceed on his/her adventure.

6. Coda: The whole story is left somewhat vague and is not fully explained: while it becomes clear the split personalities were triggered as a form of self-defense due to a traumatic childhood and an abusive, violent father, it is not fully disclosed whether they happened after one sister was actually killed, or as a means of protecting a single daughter from the abuses of her father by creating an imaginary twin who, ultimately, rebelled against her parent and killed him. In this postmodern scenario - where narrative structures are inverted and are without any simple ending - the story stays alive (as do vampires!). The story also involves very dark, mature themes which open up the possibility of players' selfreflection regarding the seriousness of domestic violence and sexual abuse; topics that are too often avoided, unvoiced or silenced in real life. The vampires in this game signify the return of the repressed.

Suddenly the simplistic 'good versus evil' scenario of "Dracula", the folklore aspects of which are imbued with a colonial orientalist imaginary of the threat of 'the Other', becomes a complex intersubjective fight with the multiplicity of self, akin to the Southern vampire genre in which vampiric beings are humanised and struggle with complex morals and desires. In this postmodern turn, the bloodiness of "Bloodlines" suggests that humans are not self-identical (there is no one self with a singular storyline throughout life), and, as is stated in text of the above screenshot, bloodlines are "tainted". In other words, we have never been pure, nor have we been in possession of simply one identity. 


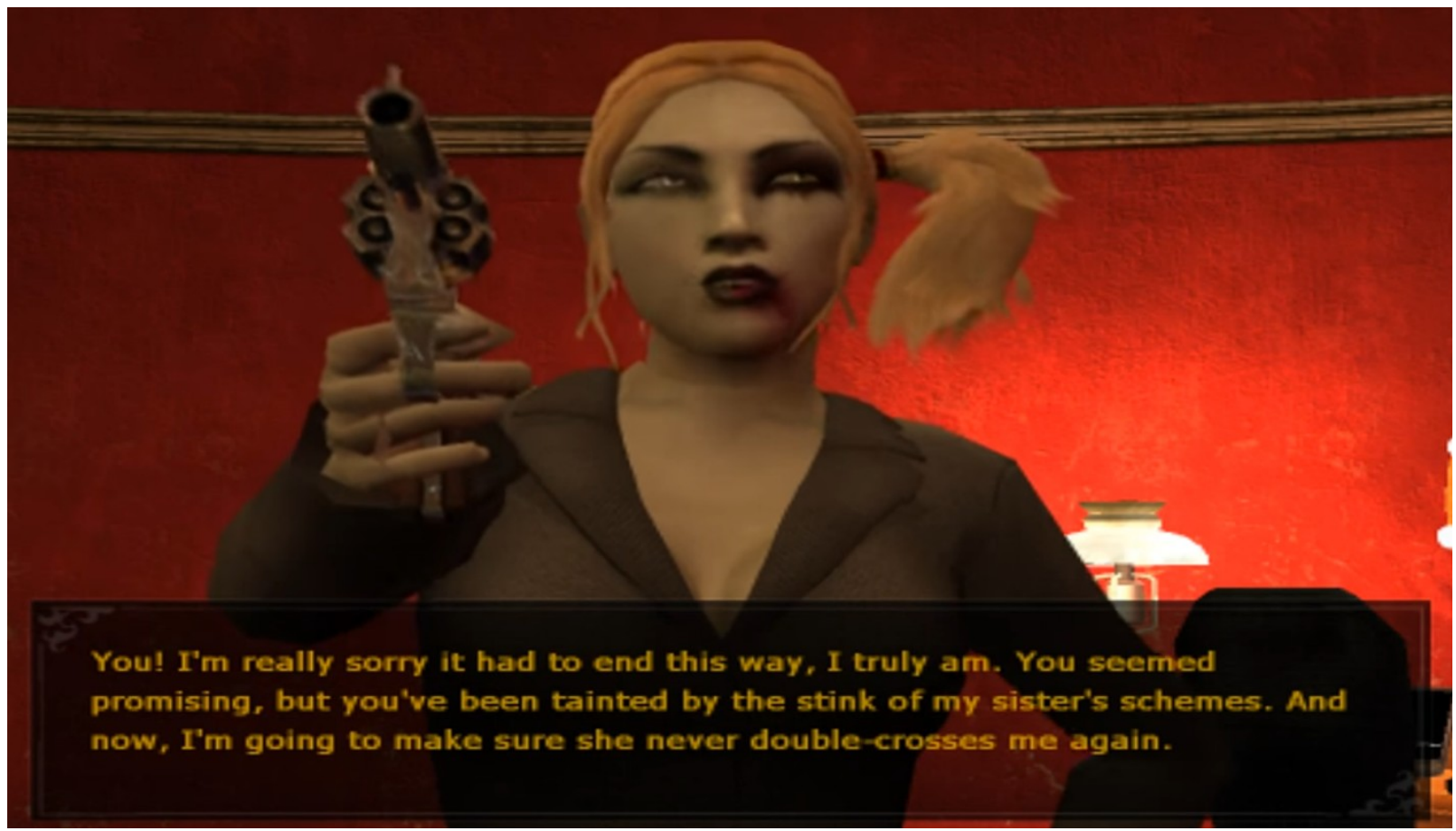

Figure 6. The dramatic twist. Therese and Jeanette turning against each other (and the player) in a dramatic plot twist unveiling a case of split personality.

\section{“Tainted": Mythology as inspiration for new multisensory experiences}

European and American folklores are not the only ones with a tradition regarding vampires. Asia harbours multifarious vampiric beings, among numerous other bloodsucking monstrosities. Southeast Asia, in general, and the Malay Archipelago (Nusantara), in particular, have a rich cultural heritage involving female vampire-ghosts - whose characteristics rest in the liminal realm between bloodthirsty vampire and ghostly apparition. Perhaps the most famous of these is Pontianak, a myth from early, animistic, Malaya, which continues to haunt the contemporary metropolises of Malaysia and Singapore.

This myth tells the story of a beautiful woman who dies during childbirth (or during the forty days of 'uncleanliness' post childbirth, or is the still born baby). ${ }^{13}$ The vampire-ghost was described by the anthropologist W. W. Skeat in his classic 1900 study Malay Magic:

${ }^{13}$ The term Pontianak is believed to be a contraction of the Bahasa Melayu phrase 'perempuan mati beranak', referring to a woman who dies during childbirth. The translation of the term is significant as it problematises the description from the 1900 text by Skeat, who translates Pontianak as the (grown up) stillborn vampiric child of the dead women rather than the woman who dies during labour, whom he identifies as the Langsuir (Skeat, 1984 [1900], p. 219; see Maulod, 2009, pp. 18-21 for critique). However, Skeat 
eTropic 16.1 (2017): 'Tropical Liminal: Urban Vampires \& Other Bloodsucking Monstrosities' Special Issue I 60

She may be known by her robe of green, by her tapering nails of extraordinary length (a mark of beauty), and by the long jet black tresses which she allows to fall down to her ankles - only alas! (for the truth must be told) in order to conceal the hole in the back of her neck through with she sucks the blood of children! These vampire-like proclivities of hers may, however, be successfully combated...if you are able to catch her, cut short her nails and luxuriant tresses, and stuff them into the hole in her neck, she will become tame and indistinguishable from an ordinary woman, remaining so for years. Cases have been known, indeed, in which she has become a wife and a mother, until she was allowed to dance at a village merrymaking, when she at once reverted to her ghostly form and flew off into the dark and gloomy forest from whence she came. (Skeat, 1984 [1900], p. 219).

The myth of Pontianak manifested from oral tradition, and colonial ethnographic documentation, into cinematic form during the 'golden era' of the film production industry of Malaya (whose studios were located in Singapore). Her presence in film was immensely popular. ${ }^{14}$ It is significant that the myth of Pontianak emerged as an indigenous form of the cinematic horror genre at the same time as Malaya was gaining independence from colonial Britain in 1957, thus giving birth to the state of Malaysia (which included Singapore, Sarawak and Sabah) in 1963, before undergoing a metaphoric still birth when Malaysia and Singapore split in 1965. The Malay-Singapore union had lasted less than 23 months, and was dramatically aborted after political tensions erupted into bloody racial violence in Singapore in July and September 1964. The myth of Pontianak, with its strong ties to death during birth, was thus manifesting in popular culture as the Malay state was undergoing its own birthing difficulties.

The split between Malaysia and Singapore signalled the 'death' of the region's film industry (Tan, 2010 , p. 152). As each of these countries set out to rapidly modernise it was deemed necessary to reject cultural heritage, including myth; and to embrace rationalism, discipline and order. In effect, this can be analysed as the repression of the feminine and identification with the masculine ( $\mathrm{Ng}, 2017$ [2014], p. 450-452). Arts and culture diminished as business and industry thrived. Pontianak was, literally, suppressed. In Malaysia, censorship laws of the 1960s and '70s, following strictures of Islam, banned storylines that were "too scary, gruesome, violent or bloody" (Surin, 2005, cited in Aquilia, 2006, p. 437). In Singapore, censorship was not as strict regarding the horror genre, however, after the race riots, policies promoted multiculturalism and religious tolerance, and therefore portrayals of ghosts or spirits were censored if the fear that they might incite racial or religious disharmony (Aquila, 2006, p. 437). Then, suddenly, with Malaysia's

does note, that both the mother and child share the same characteristics. This mother-child interchange still occurs in modern texts of Pontianak.

${ }^{14}$ She first appeared in the highly successful Cathay-Keris Film production entitled Pontianak (1957), rapidly followed by Dendam Pontianak (1957) and Sumpah Pontianak (1958), to form the Pontianak trilogy, followed by Pontianak Kembali (1963), and Pontianak Gua Musang (1964). The competing Malay Film Production studios of Shaw Bros were also making Pontianak movies, starting with Anak Pontianak (1958), and followed by Pusaka Pontianak (1965). (Millet, 2006, pp. 44-45). 
eTropic 16.1 (2017): 'Tropical Liminal: Urban Vampires \& Other Bloodsucking Monstrosities' Special Issue I 61

relaxing of censorship in 2003, Pontianak re-emerged from the shadows, appearing once again on the silver screen in 2004 in Pontianak Haram Sundal Malam (Pontianak Scent of the Tuber Rose). This film represents the return of the feminine and the culturally repressed, and is also a return to the body and senses.

Many scholarly analyses of Pontianak and her vampire-ghost sisters associate her with the ability to disturb and threaten dominant patriarchal order (Lee \& Balaya, 2016; Ng, 2017 [2014]; Izharuddin, 2015; Nicholas \& Kline, 2010; Nicholas, Ganapathy \& Mau, 2012; Tan, 2010, pp. 153156; Ong, 1988). Andrew $\mathrm{Ng}$ Hock Soon articulates cultural anxieties and the representation of women:

In a region noted for its strict adherence to gender hierarchies that plot women as secondary and inferior to men... its horror films have proven refreshingly dissident in their subtle redrawing of gender boundaries. Women, when transformed into or aligned with monsters, discover a new and empowered sense of self otherwise denied them. (2017 [2014], p. 444).

Similarly, Lundberg (2008) in her ethnographic fieldwork carried out in the house and on the property which was used as one of the film locations for Pontianak Haram Sundal Malam, argues that the female vampire-ghost "threatens the civilising attempts to tame nature, the body, the primitive and the irrational" (p. 12); qualities associated with the feminine and the liminal. These darker, wilder forms of being, prowl 'civilised' spaces - including the space of Singapore as emblematic of the most modern, efficient and rational city in Southeast Asia. Liminal beings such as vampires can thus never be totally banished (nor domesticated under patriarchal law), they always return (or escape). As Sophia Siddique Harvey argues, this persistent "return of the repressed' is a form of haunting"; a 'spectral tropicality' (2008, p. 24).

Myths of vampires, including the female Pontianak, are not relegated to some forgotten or hidden past; they are here in the present, alive in the stories we tell, including those told through popular culture and new media. In the myths and films of Pontianak her features of beauty, long dark hair, her flowing robes (which have changed from the green of Skeat's description to white) and her sudden transformation into a monstrous vampire-ghost, are all common motifs - as are the banana tree and the scent of flowers. She is said to live among banana trees, while the scent of flowers hints of her imminent apparition. In most stories the scent of frangipani, a tree common to graveyards in the Malay Archipelago, signifies her ghostly presence; however, in the film Pontianak Harum Sundal Malam her scent was that of tuber rose. Many scenes in the film depict this flower to signify immanent threat: either the sexualised masculine threat to the beautiful pregnant woman which would end in her horrific and bloody death and thus turn her into a Pontianak seeking revenge; or subsequently to signal the frightful apparition of the Pontianak in her vampire-ghost form. It is this sensory - and sensual - dimension of smell that is the latest aspect to emerge in video games. 


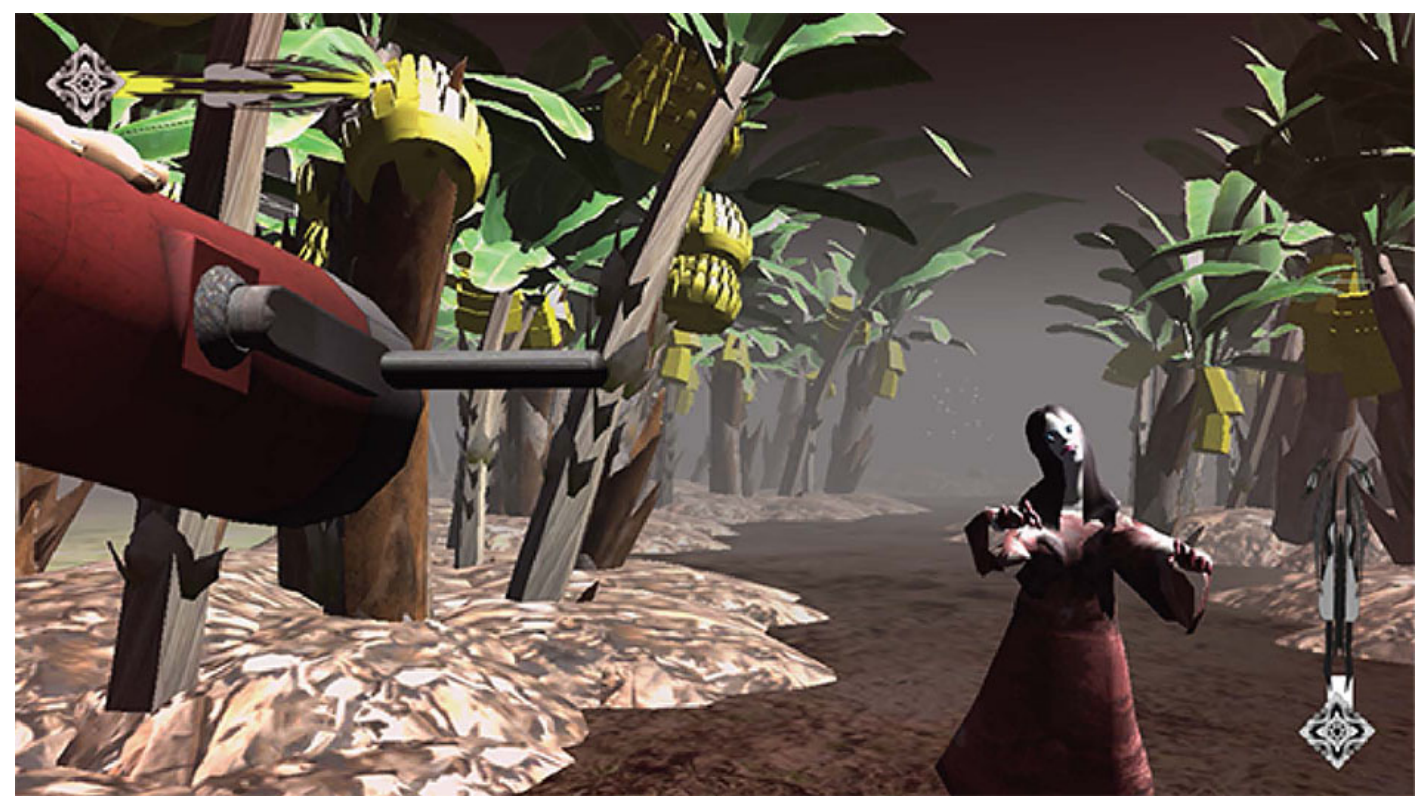

Figure 7. Screenshot from "Tainted", featuring Pontianak in a tropical setting of banana trees. With thanks to Raymond K.C. Koh for the image and permission for use (personal communication, 6 April 2017).

With a renewed emphasis on creative industries in both Singapore and Malaysia, and an expanding Southeast Asia digital media industry, ${ }^{15}$ it is not surprising that more game developers, including students, are starting to look deeper into their own cultural heritage to find new sources of inspiration. "Tainted" (Ranasinghe, 2016) was a research/student short game developed in conjunction between two Singapore-based institutions, the National University of Singapore and ITE College Central. While the game itself is very straightforward with essentially no designer story and very simple player stories built around the basic "hide and seek" gameplay concept with players trying to hide and avoid a Pontianak for as long as possible (Figure 7); it nevertheless manages to open up novel and interesting storytelling opportunities through the senses.

The novelty aspect of this game lies in the ability to tie real olfactory cues to the gameplay with different scents (jasmine, pineapple, mango and banana) being released by a connected USB device (Figure 8). Scents become, then, an integral part of the gameplay, providing additional status information and hints for the player, which, once understood (e.g., a banana smell hints at the close proximity of a Pontianak ready to strike), also play a pivotal role in triggering specific emotions typical of the 6-11 Framework - such as fear - which are central to the intended experience. Here, AGE analysis (Figure 9) shows obvious similarities with the original Imagic's Dracula (Figure 3) albeit simplified to its core elements to support a very straightforward gameplay where players can only hide but have no way to fight back and are ultimately doomed to be captured by the lurking monster.

15 See https://newzoo.com/insights/articles/newzoo-report-1-1bn-southeast-asian-games-market-todouble-by-2017/ 


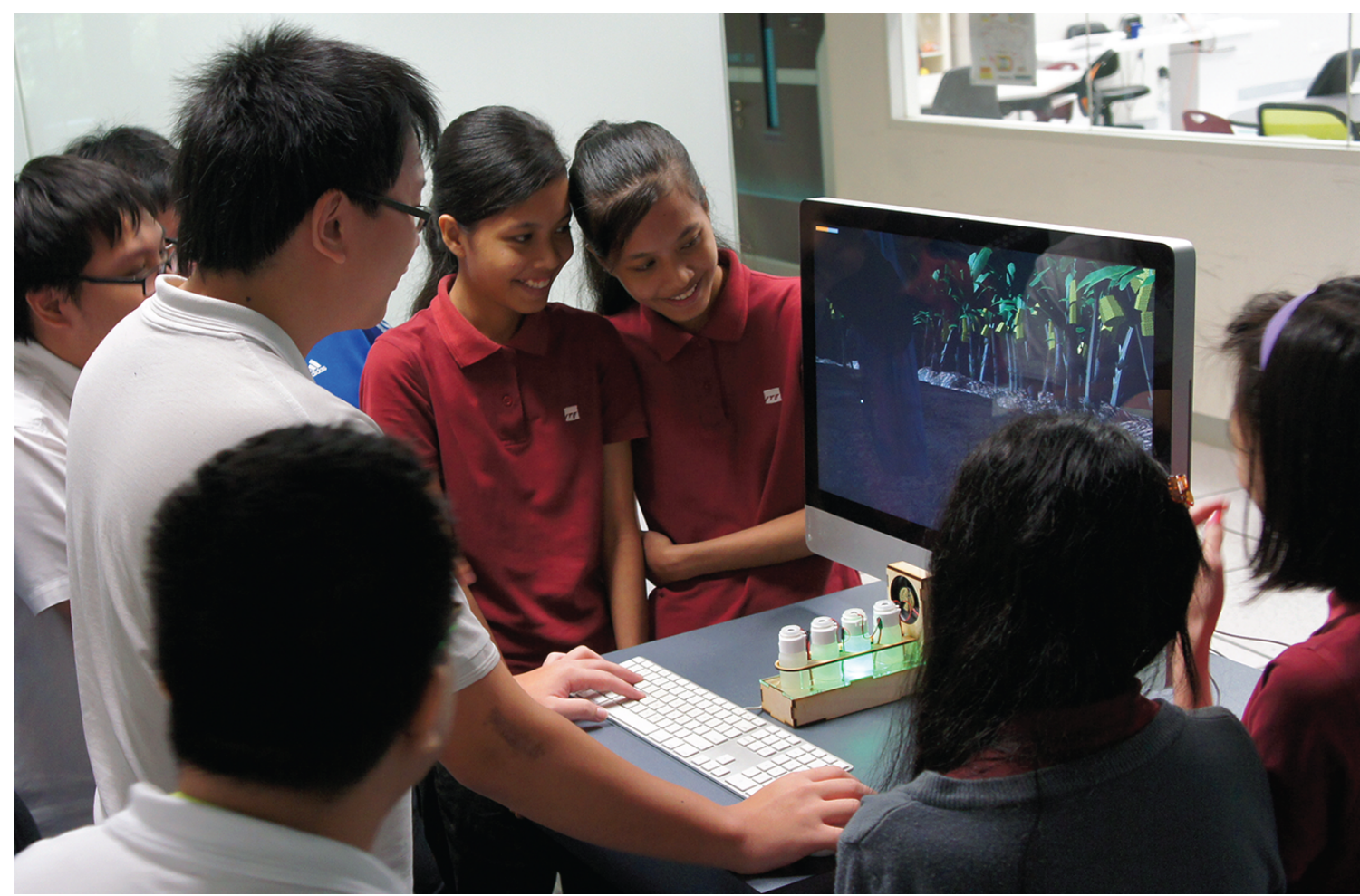

Figure 8. People playing "Tainted", a student/research project jointly developed by ITE and NUS, where a USB module can release different scents as an integral part of the story progression (@ NUS 2016)

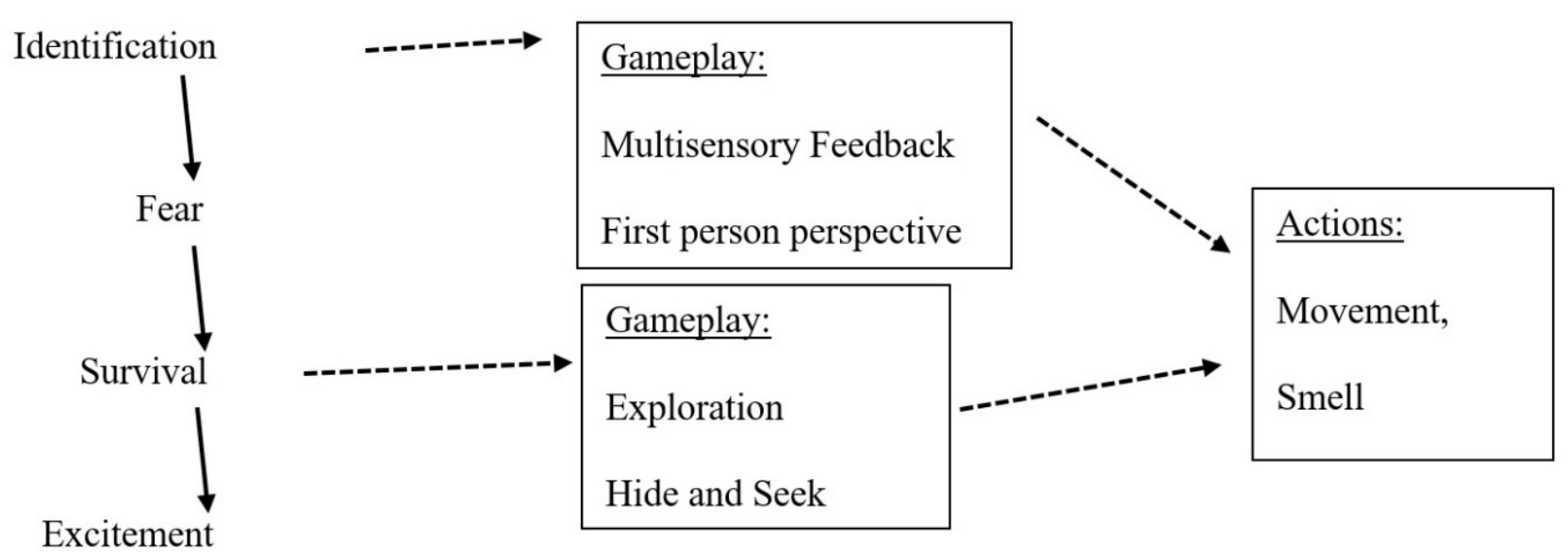

Figure 9: "Tainted” (ITE/NUS 2016) AGE Analysis. 
eTropic 16.1 (2017): 'Tropical Liminal: Urban Vampires \& Other Bloodsucking Monstrosities' Special Issue I 64

\section{Vampires and video games: Without conclusion}

Vampire stories have been a central component in myth and folklore around the world for centuries and have inspired countless fascinating renditions of these mythic tropes through popular culture such as literature and film that, importantly, resonate with real-life issues of particular places and times - including fear of 'the Other' during the colonial period when England and Europe were so dependent on tropical colonies and their peoples; fear of the intermixing of blood as demonstrated in the steamy sub-tropical vampire stories of the American deep south with their social anxieties over cultural and racial issues; and fear of the feminine as recalled through the monstrous female vampire-ghost in the Malay context. In turn, interactive digital media products like games have often relied on motifs from these traditions involving different vampirical creatures and, in some cases, with surprising and original approaches and results.

Even in the early days of the game industry, "Dracula" for Intellivision, for example, showed it was potentially great fun to play as the shadow figure or vampire and not necessarily as a vampireslayer, offering a varied set of possibilities for the emergence of emotionally engaging player's stories, despite the technical limitations of the hardware that the game ran on. As the gaming medium, as well as the underlying technology advanced, making possible the depiction of more complex designer's stories, games like "Vampires the Masquerade: Bloodlines" stood out as an exemplary game that also demonstrated how interesting stories delving into serious and dramatic topics can be important in capturing players' full attention. However, this doesn't necessarily mean there is not room for simpler, yet original kinds of experience, for instance, such as the use of olfactory senses produced by "Tainted". In this game, an unconventional use of technology demonstrates that there is still plenty to explore in telling stories based on cultural myths and in engaging players emotionally by relying on sensual experiences, like smell. Moreover, with emerging technologies like Virtual Reality, even more possibilities are likely to open up and be developed in order to tell new stories or re-imagine existing ones in different ways, making them suitable for very diverse audiences.

Storytelling and game analysis methods like those discussed in this paper may help researchers and game designers in dissecting different games in order to gain insights into how they work, ultimately helping creators to perfect their craft and conceptualize even more engaging and, possibly, terrific experiences. Additionally, game design offers an opportunity for people to tap into their cultural heritage of myths and folklore in order to reinvigorate stories that, in turn, pertain to real issues in the world. This paper has demonstrated the relationship of vampire myths, folklore, literature and film, with cultural historical issues of colonialism, racism and patriarchy - issues that remain highly relevant to contemporary societies. As observed by the famous anthropologist Claude Levi Strauss (1978), myths continue to write themselves through the stories we tell. Vampires will continue to rise in new forms of story telling, including video games. However, in order to create engaging games and intriguing storylines, we urge that it is also necessary to pay attention to the details of the various vampire myths and their cultural contexts. 
eTropic 16.1 (2017): 'Tropical Liminal: Urban Vampires \& Other Bloodsucking Monstrosities' Special Issue I 65

\section{References}

Aarseth, E. (2001) Computer game studies, year one. Game Studies, 1(1), 1-15.

Aquila, P. (2006). Westernizing Southeast Asian cinema: C-productions for 'transnational' markets. Continuum: Journal of Media \& Cultural Studies, 20(4), 433-445.

Baba, S. (Prod.). (2004). Pontianak: Haram sundal malam [Motion picture]. Kuala Lumpur: Golden Satellite and Persona Pictures.

Ball, A. (Prod.). (2008-2014). True blood [Television series]. United States of America: HBO.

Carrigan, J. A. (1959). Yellow fever in New Orleans, 1853: Abstractions and realities. The Journal of Southern History, 15 (3), 339-355.

Dillon, R. (2010). On the way to fun. Natick: AK Peters.

Dillon, R. (2011). The golden age of video games. Boca Raton: CRC Press.

Dillon, R. (2016). Towards the definition of a framework and grammar for game analysis and design. In M. J. P. Wolf (Ed.), Video games and gaming culture. Critical concepts in media and cultural Studies, 2(39), (pp.188-193), New York, NY: Routledge.

'Dracula' (1982) [video game]. Los Gatos, CA: Imagic for Intellivision.

Estella, R. (Prod). (1958). Anak Pontianak. Malaya (Singapore): Malay Film Productions (Shaw Bros.).

Estella, R. (Prod). (1963). Pontianak kembali. Malaya (Singapore): Cathay-Keris Film Productions.

Estella, R. (Prod). (1965). Pusaka Pontianak. Malaya (Singapore): Malay Film Productions (Shaw Bros.).

Frasca, G. (1999) Ludology meets narratology: Similitudes and differences between (video) games and narrative. Retrieved from www.ludology.org

Frasca, G. (2003) Ludologists love stories, too: Notes from a debate that never took place. Retrieved from www.ludology.org

Foucault, M. (1979). The history of sexuality, volume 1: An introduction (R. Hurley, Trans.). London: Allen Lane. (Original work published 1976).

Foucault, M. (1984). Of other spaces: Utopias and heterotopias (J. Miskowiec, Trans.) Architecture/Movement/Continuité. Retrieved from http://web.mit.edu/allanmc/www/foucault1.pdf

Galloway, A. R. (2006) Gaming: Essays on algorithmic culture. Minneapolis, MN: University of Minnesota Press.

Harvey, S.S. (2008). Mapping spectral tropicality in 'The Maid and Return to Pontianak'. Singapore Journal of Tropical Geography, 29, 24-33.

Izharuddin, A. (2015). Pain and pleasures of the look: The female gaze in Malaysian horror film. Asian Cinema, 26(2), 135-152.

Kerlow, I., Kadafi, M., Zhuang, Ha., Zhuang, He., Azlin, A. and Suhaimi, A. (2012). Earth girl: A multi-cultural game about natural disaster prevention and resilience. In A. Nijholt, T. Romão, \& D. Reidsma (Eds.) Advances in Computer Entertainment. Lecture Notes in Computer Science, Vol. 7624 (pp. 521524). Berlin: Springer.

Klapcsik, S. (2012). Liminality in fantastic fiction: A poststructuralist approach. London: McFarland \& Company.

Kubrick, S. (Dir. \& Prod.) (1980). The Shining. United States of America: Warner Bros.

Labov, W. (1972). The transformation of experience in narrative syntax, In W. Labov (Ed.), Language in the inner city (pp. 354-397). Philadelphia, PA: University of Washington Press.

Labov, W. (1997). Some further steps in narrative analysis. Journal of Narrative and Life History, 7, 395415. 
eTropic 16.1 (2017): 'Tropical Liminal: Urban Vampires \& Other Bloodsucking Monstrosities' Special Issue I 66

Lee, J. and Liu, M. (2016). Design of fantasy and their effect on learning and engagement in a serious game. In R. Zheng, \& M. Gardner (Eds.), Handbook of research in serious games for educational applications (pp. 197-216). Hershey, PA: IGI Global.

Lee, Y. B. \& Balaya, S. (2016). From international horror films to the local Filem Seram: Examining the cinematic identity and roles of the Malaysian Pontianak. Kemanusiaan, 23(2), 161-174.

Lévi-Strauss, C. (1978). Myth and meaning. London: Routledge and Kegan Paul.

Lundberg, A. (2008). Material poetics of a Malay house. The Australian Journal of Anthropology, 19(1), 116.

Marins, D.R., Justo, M., Chaves, B., D'Ipolitto, C., Xexeo, G. (2011). Smartrabbit: A mobile exergame using geolocation. In), 2011 Brazilian Symposium on Games and Digital Entertainment (SBGAMES (pp. 232-240). Retrieved from: https://pdfs.semanticscholar.org/2bcc/d4fc1028fe585e751e782976cf053b8971dd.pdf

Maulod, N. A. (2009). The haunting of Fatimah Rock: History, embodiment and spectral urbanism in Singapore [Masters Thesis]. Retrieved from National University of Singapore http://scholarbank.nus.edu.sg/handle/10635/17340

Millet, R. (2006). Singapore cinema. Singapore: Editions Didier-Millet.

Mott, T. (2010). 1001 Games you must play before you die. London: Universe.

$\mathrm{Ng}, \mathrm{A}$. H. K. (2017). Sisterhood of terror: The monstrous feminine of Southeast Asian horror cinema. In $\mathrm{H}$. M. Benshoff (Ed.), A companion to the horror film. West Sussex: Wiley Blackwell/John Wiley \& Sons, Inc. (First published in 2014).

Nicholas, C. L., Ganapathy, R. \& Mau, H. (2012). Malaysian Cerita Hantu: Intersections of race, religiosity, class, gender, and sexuality. Journal of International and Intercultural Communication, 6(3), 163182.

Nicholas, C. L \& Kline, K. N. (2010). Cerita Pontianak: Cultural contradictions and patriarchy in a Malay ghost story. Storytelling, Self, Society, 6, 194-211.

Ong, A. (1988). The production of possession: Spirits and the multinational corporation in Malaysia. American Ethnologist, 15(1), 28-42.

Pile, S. (2003). Perpetual returns: Vampires and the ever-colonized city. In R. Bishop, J. Phillips, \& W. W.Yeo (Eds.), Postcolonial urbanism: Southeast Asian cities and global processes (pp. 265-284). New York, NY: Routledge, Taylor \& Francis Group.

Polidori, J. W. (1819). The vampyre; A tale. Retrieved from https://www.gutenberg.org/files/6087/6087h/6087-h.htm

Rao, B.N. (Prod.) (1957). Dendam Pontianak. Malaya (Singapore): Cathay-Keris Film Productions.

Rao, B.N. (Prod.) (1957). Pontianak. Malaya (Singapore): Cathay-Keris Film Productions.

Rao, B.N. (Prod.) (1958). Sumpah Pontianak. Malaya (Singapore): Cathay-Keris Film Productions.

Rao, B.N. (Prod.) (1964). Pontianak gua musang. Malaya (Singapore): Cathay-Keris Film Productions.

Ranasinghe, N., \& Koh, R. K. C., et al. (2016). Tainted. Sense of wonder night 2016, Tokyo Game Show 2016. Maihama, Chiba, Japan. CESA/Nikkei Business Publications, Inc. Retrieved from http://expo.nikkeibp.co.jp/tgs/2016/business/en/event/sown/presentation.html\#pre2

Reichelt, D (2017). Designing games that stand out. Casual Connect Asia Conference, Singapore.

Rice, A. (1976). Interview with a vampire. New York, NY: Ballantine Books.

Rouse, R. (2004): Game design: Theory and practice. Sudbury, MA: Wordware Publishing.

Said, E. W. (1979). Orientalism. New York, NY: Vintage Books Edition. (First published in 1978). 
eTropic 16.1 (2017): 'Tropical Liminal: Urban Vampires \& Other Bloodsucking Monstrosities' Special Issue I 67

Skeat, W. W. (c.1984) [1900]. Malay Magic: Being an introduction to the folklore and popular religion of the Malay Peninsula. Singapore: Oxford University Press.

Stoker, B. (1897). Dracula. Retrieved from http://www.gutenberg.org/files/345/345-h/345-h.htm

Straits Times, The (1957, 26 April). Advertisement, p. 9. Retrieved from http://eresources.nlb.gov.sg/newspapers/Digitised/Article/straitstimes19570426-1.2.126.2

'Tainted' (2016) [video game]. Singapore: ITE/NUS for PC.

Tan, K. P. (2010). Pontianaks, ghosts and the possessed: Female monstrosity and national anxiety in Singapore Cinema. Asian Studies Review, 34, 151-170.

'Vampire the Masquerade: Bloodlines' (2004) [video game]. Santa Monica, CA: Activision for PC. 